\title{
Speed of Sound in Water by a Direct Method
}

\section{Martin Greenspan and Carroll E. Tschiegg}

\begin{abstract}
The speed of sound in distilled water was measured over the temperature range $0^{\circ}$ to $100^{\circ} \mathrm{C}$ with an accuracy of 1 part in 30,000 . The results are given as a fifth-degree polynomial and in tables. The water was contained in a cylindrical tank of fixed length, terminated at each end by a plane transducer, and the end-to-end time of flight of a pulse of sound was determined from a measurement of the pulse-repetition frequency required to set the successive echoes into time coincidence.
\end{abstract}

\section{Introduction}

The speed of sound in water, $c$, is a physical property of fundamental interest; it, together with the density, determines the adiabatic compressibility, and eventually the ratio of specific heats. The variation with temperature is anomalous; water is the only pure liquid for which it is known that the speed of sound does not decrease monotonically with temperature.

There is also a practical interest in $c$ in that water is used as a standard liquid for the calibration of instruments that measure the speed of sound in liquids automatically, both in the laboratory and in the field. In fact, it was in connection with the calibration of such "velocimeters" [1] ${ }^{2}$ that our interest in this work was first aroused. In the first place, the available data scatter widely, as recent summaries [2, 3] clearly show. In many cases, the discrepancies far exceed the claimed accuracy or at least the precision of the methods, even when the methods compared are the same. In the second place, there exists no set of data that gives a smooth variation with temperature over any considerable range. In particular, the best of these data yield calibration curves for our velocimeters which are badly curved instead of straight (as they should be), and about which the data scatter irregularly, but reproducibly. The results here presented are free of these objections.

\section{Method}

At the top of figure 1 is a schematic of the apparatus. The sample is confined in a tube of which the ends are plane, parallel, electroacoustic transducers, quartz crystals in this case. If the left-hand crystal, say, is excited by a short pulse from the blocking oscillator, the oscilloscope, which measures the voltage on the right-hand crystal, will show a received pulse and a series of echoes, as indicated in idealized form on the line below (fig. 1). The pulse repetition frequency of the blocking oscillator is controlled by a sine-wave oscillator, and if this frequency were adjusted so that each blocking oscillator pulse coincided with the first received pulse of the next preceding cycle, then the oscillator period would equal the time of flight of the pulse. However,

1 This work was supported in part by the Office of Naval Research under contract NA-onr-70-48.

${ }_{2}$ Figures in brackets indicate the literature references at the end of this paper. as the two pulses have different shapes, the accuracy with which the coincidence could be set would be very poor. Instead, the oscillator is run at about half this frequency and the coincidence to be set is that among the first received pulses corresponding to a particular electrical pulse, the first echo corresponding to the electrical pulse next preceding, and so on. Figure 1 illustrates the successive signals corresponding to three electrical input pulses. The input pulses fall halfway between the pulses for which the coincidence is set, so that they do not tend to overload the amplifier or distort the oscilloscope traces. The period of the oscillator, when properly set, multiplied by twice the length of the tank, is the speed of sound in the sample.

The oscilloscope trace actually looks like that shown in the inset (fig. 1). The first cycle corresponds to sound reflected from the inner faces only of the transducers, whereas the succeeding cycles correspond to sound reflected one or more times from an outer face. Therefore, the coincidence is set by maximizing the peak on either the first or second balf-cycle; the same result is obtained in either case but the second half cycle is easier to use because it is bigger. What we are measuring here is the speed corresponding to the first arrival of the signal; in a nondispersive liquid this is the same as the phase velocity. It is true that the coincidence is made at a
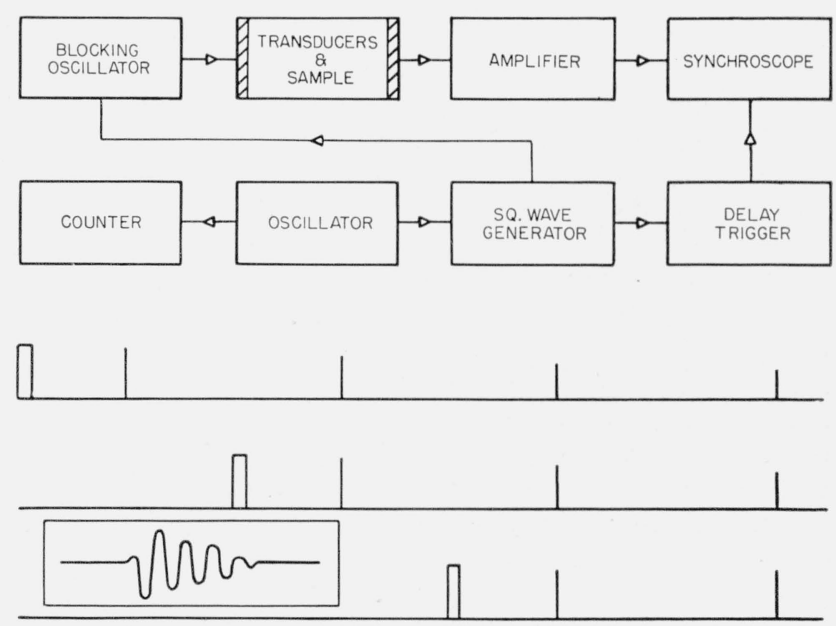

Figure 1. Schematic of method.

The three lower lines show in idealized form the events corresponding to three successive electrical pulses. The short, thick line represents the input pulse. 
time one-fourth or three-quarters of the transducer period later than the time of first arrival, by which time there is opportunity for sound traveling by paths other than the shortest to affect the location of the maximum. However, the results are independent of whether the first or second half cycle is used; they are also not affected by substituting crystals of twice the thickness, or by changing the diameters of the tank, or of the hot electrodes. These results lead us to believe that the error introduced by this maximization technique is negligible.

The question has been examined also in another way. Suppose a coincidence to have been made at frequency $f$; others can then be made at submultiples of $f$. At the frequency $f / 2$ for instance, the first received pulse corresponding to a particular input pulse coincides with the second echo (not the first, as before) corresponding to the electrical pulse next preceding, and so on. Effectively, the sound pulse is timed over a path twice as long as before. It is found that the measurements at $f$ and near $f / 2$ are substantially identical, so that the error in question is less than, or at most comparable to, the experimental error of the time measurement.

\section{Apparatus}

\subsection{The Delay Line}

The disassembled delay line is shown in the photograph, figure 2. The length of the tank is about $200 \mathrm{~mm}$, and the bore about $13 \mathrm{~mm}$. The filling holes are sealed by plugs having Teflon gaskets; a small hole in one plug provides pressure release.

The tank is of a chromium steel ${ }^{3}$ which, after heat treatment, takes a good optical finish. Because this steel is not so corrosion resistant as the nickelchromium stainless steels, the bore of the tank was heavily gold plated.

The ends of the tank are optically flat and parallel to within less than $1 \mu$. To these ends are carefully wrung the $0.8-\mathrm{mm}$ thick $\mathrm{x}$-cut quartz crystals, which also are optically flat. The caps, when bolted on, clamp the crystals through neoprene O-rings. A coaxial cable passes through a seal in each cap, and the center conductor makes contact with the outer (hot) electrode of the crystal through a light spring.

The outer electrode is a $9 \mathrm{~mm}$ circle of aluminumbacked pressure-sensitive adhesive tape. The inner (ground) electrode is of fired-on gold and is about $12 \mathrm{~mm}$ in diameter. Contact is made through a light gold-plated helical spring which touches the electrode around the edge and bears on a shoulder machined into the bore. The inner electrodes and springs are unnecessary if the sample has high conductivity or a high dielectric constant; they are usually omitted for water and aqueous solutions of salts. Figure 3 is a schematic drawing of one end of the assembly.

The length of the tank was measured at $20^{\circ} \mathrm{C}$, and the coefficient of thermal expansion of the steel was measured on a sample cut from the same bar as

${ }^{3}$ Firth-Sterling type】B-440A.

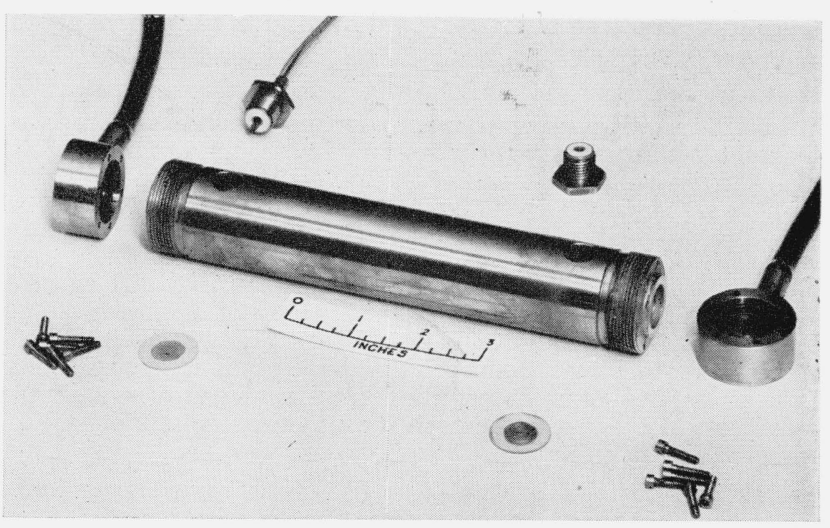

Figure 2. Delay line, disassembled.

Above the tank are the plugs which close the filling holes, and at the ends are the caps through which pass the electrical cables and which also clamp the crystals seen in the foreground.

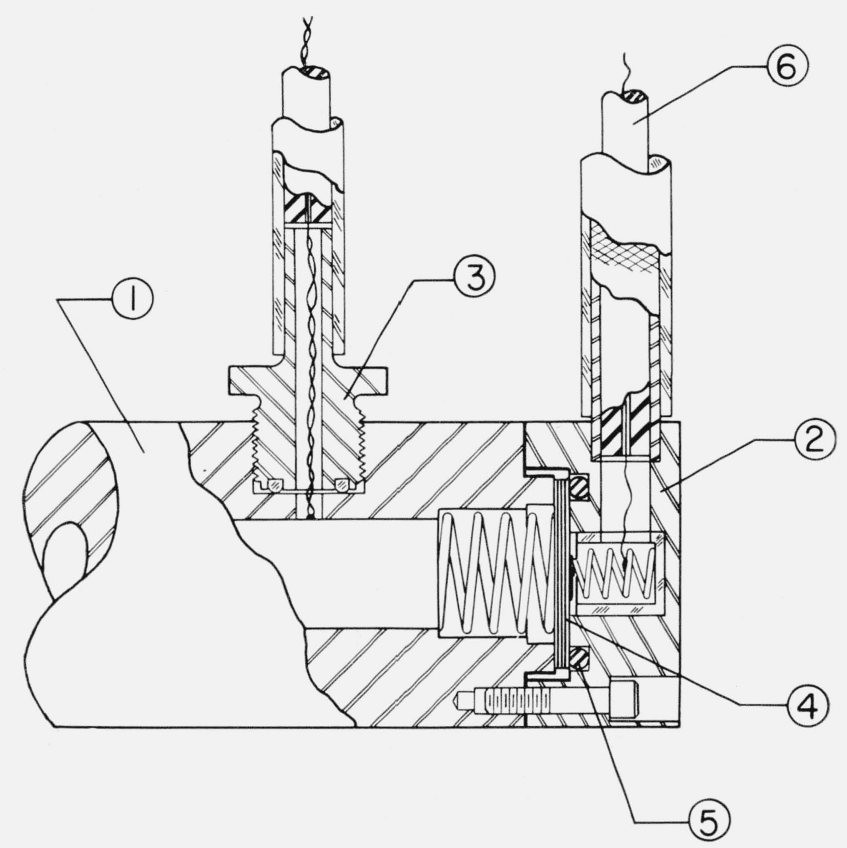

Figure 3. Schematic of one end of the tank, showing the crystal and cap assembly.

1, Tank; 2, cap; 3, plug sealed with Teflon O-ring (thermocouple passes through pressure relief tube); 4 , quartz crystal wrung onto end of tank (springs make contact to electrodes); 5 , neoprene O-ring; and 6, coaxial cable.

was the tank and heat-treated together with it. From these data, the length of the sound path is known to better than 2 parts in $10^{5}$ at any temperature between $0^{\circ}$ and $100^{\circ} \mathrm{C}$. It is, of course, necessary that the crystals be wrung down with great care so that the fringes disappear all around the periphery, to achieve this accuracy. The clamping gaskets must bear directly over the contacting surface and not spread out over the unsupported area, else the crystal will bend. With these precautions, the delay line may be disassembled and reassembled repeatedly with reproducible results. If the crystals have been properly wrung on and clamped, they cannot be removed by hand after several days, but must be soaked off. 


\subsection{The Electronics}

The electronic circuits (fig. 1) are, for the most part, conventional. However, the oscillator and the pulse-forming circuits must be exceptionally free of jitter. In addition, the oscillator must be provided with fine frequency control, so that it can be set within the required sensitivity of measurement, and it must be so stable that the frequency does not change during the counting time by enough to alter the count by more than one.

The blocking oscillator produces a pulse about 100 $\mathrm{v}$ high and 0.05 to $0.25 \mu \mathrm{sec}$ wide. It is best driven by a large, fast pulse such as is gotten by differentiation of a square wave derived, in turn, from the sinewave generator. ${ }^{4}$ The jitter may be reduced further by means of a narrow band filter after the oscillator.

The receiving circuit consists simply of a short length of low-capacitance cable, a wide band (5.5 $\mathrm{Mc}$, in this case) amplifier of gain 100 to 1,000, and a high-frequency type oscilloscope equipped with fast sweeps. The sweep is triggered from the oscillator through a variable delay; the necessary delay time is about half the oscillator period.

\subsection{Temperature Control and Measurement}

The delay line, suspended from its cables, is deeply immersed in a 27 gal, well-insulated, water bath. The bath is provided with 2 pump-type stirrers, 3 heating coils, and a cooling coil connected to a small refrigeration unit. The temperature of the water adjusts itself so that the losses equal the power input to the heating coils, and various temperatures are obtained simply by varying the power input. The temperature is, by this means, easily held to within less than $0.005 \mathrm{deg} \mathrm{C}$ for the interval of time required for the measurements, except that above $75^{\circ} \mathrm{C}$, or so, the variation may become $0.02^{\circ}$ or $0.03^{\circ} \mathrm{C}$; at the higher temperatures, however, the thermal coefficient of the speed of sound in water is rather low.

The temperature of the bath water is measured with a platinum resistance thermometer and Mueller Bridge. A differential thermocouple has one junction in the sample in the delay line, and one tied to the platinum thermometer; it passes through the pressure release tube (fig. 2). The thermocouple reading serves to indicate when the sample and bath water are substantially in thermal equilibrium, and measurements are made when the discrepancy is less than $0.01^{\circ} \mathrm{C}$ (somewhat greater at the high temperatures). The thermocouple and galvanometer combination was calibrated for small temperature differences against the platinum resistance thermometer so that small corrections to the temperature readings could be made.

\subsection{Samples}

The measurements here reported were made on three separate samples of water. One sample was ordinary laboratory distilled water. This was boiled

\footnotetext{
${ }_{4}^{4}$ The square-wave generator must be of the type that amplifies and then clips
} the input sine wave. The free-running, synchronized type is not suitable. and poured, while still hot, into the preheated tank. Although dissolved air has a negligible effect on the speed of sound in water [4], it is desirable to exclude air and so prevent possible bubble formation on the transducers.

The other two samples were vacuum distilled directly into the tank. The tank was placed in an ice bath and connected to a flask of distilled water. The system was then evacuated, and the water allowed to distill over at about $50^{\circ} \mathrm{C}$.

The results of the three runs were the same within the errors of measurement; the data were, therefore, combined.

\subsection{Technique}

The water bath was cooled to just above $0^{\circ} \mathrm{C}$, and the heaters were operated at low power to stabilize the temperature. (Below room temperature the refrigeration machine was run continuously.) After the readings were taken, the power input to the heaters was increased, and so on until the temperature was just below $100^{\circ} \mathrm{C}$. When the temperature was stabilized, as indicated by the constancy of the Mueller bridge reading and the near zero reading of the thermocouple galvanometer, the coincidence was set on the oscilloscope by one observer and the frequency (doubled for convenience) was measured by counting cycles for $10 \mathrm{sec}$ (about 75,000 counts) by means of an electronic counter. At the same time, another observer balanced and read the Mueller bridge and read the thermocouple galvanometer deflection.

While the temperature readings were being made, the coincidence was independently set and the resulting frequency measured three times or more. The various readings were always within the \pm 1 count inherent error (even for different observers) and the modal value was recorded. This, divided by 20 and multiplied by the length of the tank at the particular temperature, was taken as the speed of sound, $c$, corresponding to the temperature, $T$, obtained by calculation from the platinum thermometer and the thermocouple readings and the associated calibration data. All temperature calculations were made to the nearest $0.001^{\circ} \mathrm{C}$ and the final result was rounded off to the nearest $0.01^{\circ} \mathrm{C}$.

In order to insure that the coincidence was set on the proper cycle, it was first set approximately, using the coarse frequency control, at a moderate sweep speed and low oscilloscope gain, so that the entire pulse was visible on the screen. The sweep speed was then increased while the delay was readjusted to keep the proper cycle centered. Next, the gain was increased while the base line was moved off the screen to keep the point of extreme deflection centered, and the amplitude was then adjusted to a maximum using the fine frequency control.

\section{Results}

From readings taken at 83 temperatures between $0.14^{\circ}$ and $99.06^{\circ} \mathrm{C}$, the calculated values of the speed of sound were fitted by the electronic com- 


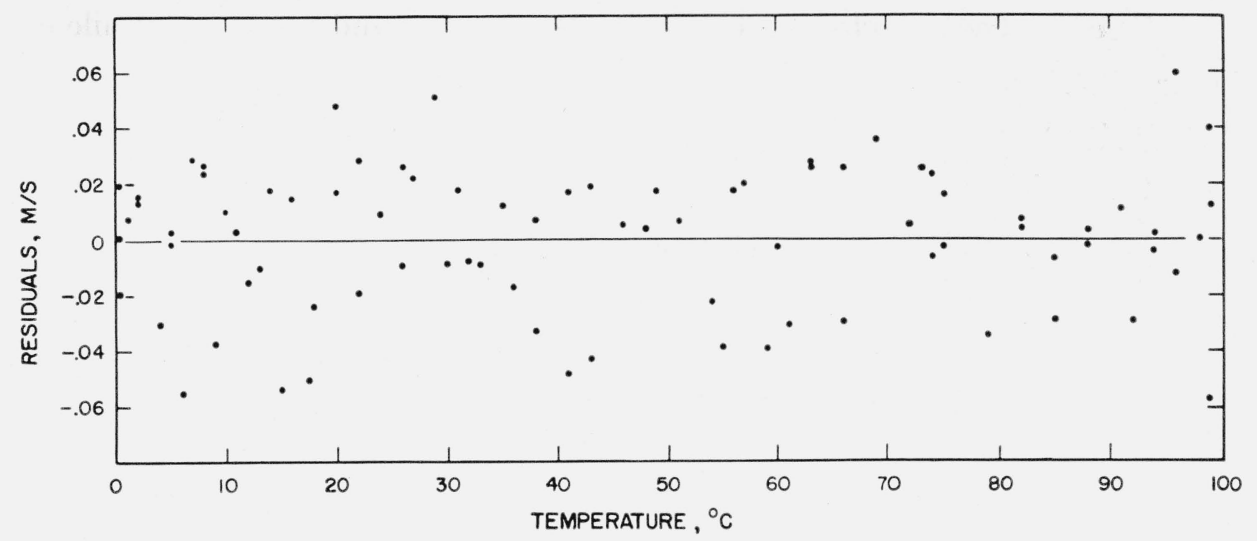

Figure 4. Deviations, $r$, of equation 1 from the data.

puter SEAC by the method of least squares, to a fifth-degree polynomial,

$$
c=\sum_{i=0}^{5} a_{i} T^{i}
$$

The reduction in the residual sum of squares over a fourth-degree polynomial, due to fitting the fifthdegree term, was statistically significant at a probability level less than 0.005 , and the deviations of the data from the fifth-degree polynomial showed no statistically significant indication of lack of randomness. The deviations are plotted against temperature in figure 4.

The values of $a_{i}$ in eq (1), for $c$ in meters per second $(\mathrm{m} / \mathrm{s})$, and $T$ in degrees $\mathrm{C}$, are: $a_{0}=1,402.736 ; a_{1}=$ $5.03358 ; a_{2}=-0.0579506 ; a_{3}=3.31636 \times 10^{-4} ; a_{4}=-$ $1.45262 \times 10^{-6}$; and $a_{5}=3.0449 \times 10^{-9}$. The standard deviation of the measurements is $0.0263 \mathrm{~m} / \mathrm{s}$, or about $17 \mathrm{ppm}$. Estimated standard deviations of the values of $c$ predicted by eq (1) were calculated for five representative temperatures. The results are given in table 1.

TABLE 1. Estimated standard deviation $(s, d$.) of values of $c$ predicted by equation 1

\begin{tabular}{|c|c|c|}
\hline \hline Temperature & \multicolumn{2}{|c|}{ s. d. } \\
\hline & & \\
\hline & & \\
\hline & $m / s$ & $p p m$ \\
0 & 0.0114 & 8.1 \\
10 & .0065 & 4.5 \\
50 & .0058 & 3.8 \\
70 & .0062 & 4.0 \\
100 & .0145 & 9.4 \\
\hline
\end{tabular}

Table 1 and figure 4 make it clear that eq (1), together with the listed constants, provides a satisfactory interpolation formula, and the errors introduced by its use are small relative to the possible systematic errors of measurement (see section 5). The values given in tables 2 and 3 were calculated from eq (1) by SEAC.

Table 2 gives the speed of sound in meters per second for each degree $\mathrm{C}$ from 0 to 100 , and table 3 gives the speed of sound in feet per second at intervals of $2 \mathrm{deg} \mathrm{F}$ from $32^{\circ}$ to $212^{\circ}$. In each case, the differences, which are listed for convenience in interpolation, were calculated from a table having more significant figures, so that on account of rounding-off errors, the tabulated differences in some cases differ by one unit in the last decimal place from the differences of the tabulated values of $c$. It is believed (see section 5) that the systematic errors do not exceed 1 part in 30,000 . The tables should, therefore, be used in the following manner. In table 2, linear interpolation should be performed to the nearest $0.01 \mathrm{~m} / \mathrm{s}$ and the final result rounded off to the nearest $0.1 \mathrm{~m} / \mathrm{s}$. The error will then not exceed one-half unit in the last place, i. e., $0.05 \mathrm{~m} / \mathrm{s}$. Linear interpolation in table 3 will yield errors that do not exceed 2 units $(0.2 \mathrm{fps})$ in the last place.

\section{Discussion}

Following is a list of the known possible sources of error and an estimate of the upper limit of each error.

\subsection{Frequency}

As already stated, the frequency was measured by counting cycles for $10 \mathrm{sec}$; the total count was about 75,000 . The inherent error is \pm 1 count, but in all cases the mode of at least three independent readings, of which, at worst, two were the same and the third different by one, was taken as the observed value. The counting error can thus be as great as 1 part in 75,000 , but as it is random, the effect on the final results is negligible, as indicated in section 4 . The 10-sec time base was obtained by division from a 1-Mc crystal oscillator which is stable to 2 parts in $10^{7}$ per week, and which was compared with signals from $W W V$ or from a local precision standard. The errors due to inaccuracies in the time base are, therefore, also negligible.

\subsection{Length of Path}

The length of the tank across its polished ends at $20^{\circ} \mathrm{C}$ was determined within $1 \mu$, i. e., 5 ppm. Thermal expansion measurements were made at $20^{\circ}, 60^{\circ}$, and $100^{\circ} \mathrm{C}$; the lengths at intermediate temperatures were calculated by quadratic interpolation. The maximum absolute error in the thermal expansion coefficient is estimated at $0.2 \mathrm{ppm}$; this accumulates to $4 \mathrm{ppm}$ at $0^{\circ} \mathrm{C}$, and to $16 \mathrm{ppm}$ at $100^{\circ} \mathrm{C}$. 
TABLE 2. Speed of sound in water, metric units

\begin{tabular}{|c|c|c|c|c|c|c|c|c|c|c|c|}
\hline$T$ & $c$ & $\Delta$ & $T$ & $c$ & $\Delta$ & $T$ & $c$ & $\Delta$ & $T$ & $c$ & $\Delta$ \\
\hline $\begin{array}{l}{ }^{\circ} \mathrm{C} \\
\\
\\
0 \\
1 \\
2 \\
3 \\
4\end{array}$ & $\begin{array}{r}m / s \\
1,400+ \\
2.74 \\
7.71 \\
12.57 \\
17.32 \\
21.96\end{array}$ & $\begin{array}{l}\mathrm{m} / \mathrm{s} \\
\\
4.97 \\
4.86 \\
4.75 \\
4.64\end{array}$ & $\begin{array}{l}{ }^{\circ} \mathrm{C} \\
\\
25 \\
26 \\
27 \\
28 \\
29\end{array}$ & $\begin{array}{r}m / s \\
1,400+ \\
97.00 \\
99.64 \\
*_{2} .20 \\
4.68 \\
7.10\end{array}$ & $\begin{array}{l}\mathrm{m} / \mathrm{s} \\
2.71 \\
2.64 \\
2.56 \\
2.49 \\
2.41\end{array}$ & $\begin{array}{l}{ }^{\circ} \mathrm{C} \\
\\
50 \\
51 \\
52 \\
53 \\
54\end{array}$ & $\begin{array}{c}m / s \\
1,500+ \\
42.87 \\
43.93 \\
44.95 \\
45.92 \\
46.83\end{array}$ & $\begin{array}{l}m / s \\
1.12 \\
1.07 \\
1.02 \\
0.97 \\
.92\end{array}$ & $\begin{array}{l}{ }^{\circ} \mathrm{C} \\
75 \\
76 \\
77 \\
78 \\
79\end{array}$ & $\begin{array}{c}m / s \\
1,500+ \\
55.45 \\
55.40 \\
55.31 \\
55.18 \\
55.02\end{array}$ & $\begin{array}{c}m / s \\
-0.01 \\
-.05 \\
-.09 \\
-.13 \\
-.17\end{array}$ \\
\hline $\begin{array}{l}5 \\
6 \\
7 \\
8 \\
9\end{array}$ & $\begin{array}{l}26.50 \\
30.92 \\
35.24 \\
39.46 \\
43.58\end{array}$ & $\begin{array}{l}4.53 \\
4.43 \\
4.32 \\
4.22 \\
4.12\end{array}$ & $\begin{array}{l}30 \\
31 \\
32 \\
33 \\
34\end{array}$ & $\begin{array}{r}9.44 \\
11.71 \\
13.91 \\
16.05 \\
18.12\end{array}$ & $\begin{array}{l}2.34 \\
2.27 \\
2.20 \\
2.14 \\
2.07\end{array}$ & $\begin{array}{l}55 \\
56 \\
57 \\
58 \\
59\end{array}$ & $\begin{array}{l}47.70 \\
48.51 \\
49.28 \\
50.00 \\
50.68\end{array}$ & $\begin{array}{l}.87 \\
.82 \\
.77 \\
.72 \\
.67\end{array}$ & $\begin{array}{l}80 \\
81 \\
82 \\
83 \\
84\end{array}$ & $\begin{array}{l}54.81 \\
54.57 \\
54.30 \\
53.98 \\
53.63\end{array}$ & $\begin{array}{l}-.20 \\
-.24 \\
-.28 \\
-.31 \\
-.35\end{array}$ \\
\hline $\begin{array}{l}10 \\
11 \\
12 \\
13 \\
14\end{array}$ & $\begin{array}{l}47.59 \\
51.51 \\
55.34 \\
59.07 \\
62.70\end{array}$ & $\begin{array}{l}4.02 \\
3.92 \\
3.82 \\
3.73 \\
3.64\end{array}$ & $\begin{array}{l}35 \\
36 \\
37 \\
38 \\
39\end{array}$ & $\begin{array}{l}20.12 \\
22.06 \\
23.93 \\
25.74 \\
27.49\end{array}$ & $\begin{array}{l}2.00 \\
1.94 \\
1.87 \\
1.81 \\
1.75\end{array}$ & $\begin{array}{l}60 \\
61 \\
62 \\
63 \\
64\end{array}$ & $\begin{array}{l}51.30 \\
51.88 \\
52.42 \\
52.91 \\
53.35\end{array}$ & $\begin{array}{l}.63 \\
.58 \\
.53 \\
.49 \\
.45\end{array}$ & $\begin{array}{l}85 \\
86 \\
87 \\
88 \\
89\end{array}$ & $\begin{array}{l}53.25 \\
52.82 \\
52.37 \\
51.88 \\
51.35\end{array}$ & $\begin{array}{l}-.39 \\
-.42 \\
-.46 \\
-.49 \\
-.52\end{array}$ \\
\hline $\begin{array}{l}15 \\
16 \\
17 \\
18 \\
19\end{array}$ & $\begin{array}{l}66.25 \\
69.70 \\
73.07 \\
76.35 \\
79.55\end{array}$ & $\begin{array}{l}3.55 \\
3.46 \\
3.37 \\
3.28 \\
3.19\end{array}$ & $\begin{array}{l}40 \\
41 \\
42 \\
43 \\
44\end{array}$ & $\begin{array}{l}29.18 \\
30.80 \\
32.37 \\
33.88 \\
35.33\end{array}$ & $\begin{array}{l}1.69 \\
1.63 \\
1.57 \\
1.51 \\
1.45\end{array}$ & $\begin{array}{l}65 \\
66 \\
67 \\
68 \\
69\end{array}$ & $\begin{array}{l}53.76 \\
54.11 \\
54.43 \\
54.70 \\
54.93\end{array}$ & $\begin{array}{l}.40 \\
.36 \\
.31 \\
.27 \\
.23\end{array}$ & $\begin{array}{l}90 \\
91 \\
92 \\
93 \\
94\end{array}$ & $\begin{array}{l}50.79 \\
50.20 \\
49.58 \\
48.92 \\
48.23\end{array}$ & $\begin{array}{l}-.56 \\
-.59 \\
-.63 \\
-.66 \\
-.69\end{array}$ \\
\hline $\begin{array}{l}20 \\
21 \\
22 \\
23 \\
24\end{array}$ & $\begin{array}{l}82.66 \\
85.69 \\
88.63 \\
91.50 \\
94.29\end{array}$ & $\begin{array}{l}3.11 \\
3.03 \\
2.95 \\
2.87 \\
2.79\end{array}$ & $\begin{array}{l}45 \\
46 \\
47 \\
48 \\
49\end{array}$ & $\begin{array}{l}36.72 \\
38.06 \\
39.34 \\
40.57 \\
41.74\end{array}$ & $\begin{array}{l}1.39 \\
1.34 \\
1.28 \\
1.23 \\
1.17\end{array}$ & $\begin{array}{l}70 \\
71 \\
72 \\
73 \\
74\end{array}$ & $\begin{array}{l}55.12 \\
55.27 \\
55.37 \\
55.44 \\
55.47\end{array}$ & $\begin{array}{l}.19 \\
.15 \\
.11 \\
.07 \\
.03\end{array}$ & $\begin{array}{l}95 \\
96 \\
97 \\
98 \\
99\end{array}$ & $\begin{array}{l}47.50 \\
46.75 \\
45.96 \\
45.14 \\
44.29\end{array}$ & $\begin{array}{l}-.72 \\
-.76 \\
-.79 \\
-.82 \\
-.85\end{array}$ \\
\hline 25 & $\begin{array}{r}97.00 \\
1,400+\end{array}$ & 2.71 & 50 & $\begin{array}{r}42.87 \\
1,500+\end{array}$ & 1. 12 & 75 & $\begin{array}{r}55.45 \\
1,500+\end{array}$ & -.01 & 100 & $\begin{array}{r}43.41 \\
1,500+\end{array}$ & -.88 \\
\hline
\end{tabular}

TABLE 3. Speed of sound in water, English units

\begin{tabular}{|c|c|c|c|c|c|c|c|c|c|c|c|}
\hline$T$ & $c$ & $\Delta$ & $T$ & $c$ & $\Delta$ & $T$ & $c$ & $\Delta$ & $T$ & $c$ & $\Delta$ \\
\hline $\begin{array}{l}{ }^{\circ} \mathrm{F} \\
\\
30 \\
32 \\
34 \\
36 \\
38\end{array}$ & \begin{tabular}{r}
\multicolumn{1}{c}{$f p s$} \\
$4,600+$ \\
2.1 \\
20.3 \\
37.9 \\
55.1
\end{tabular} & 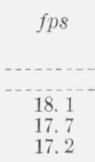 & $\begin{array}{l}{ }^{\circ} \mathrm{F} \\
\\
80 \\
82 \\
84 \\
86 \\
88\end{array}$ & $\begin{array}{c}f p s \\
4,900+ \\
25.7 \\
34.8 \\
43.7 \\
52.2 \\
60.5\end{array}$ & $\begin{array}{l}f p s \\
\\
9.4 \\
9.1 \\
8.8 \\
8.6 \\
8.3\end{array}$ & $\begin{array}{l}{ }^{\circ} \mathrm{F} \\
\\
130 \\
132 \\
134 \\
136 \\
138\end{array}$ & $\begin{array}{c}f p s \\
5,000+ \\
76.2 \\
79.2 \\
82.1 \\
84.8 \\
87.3\end{array}$ & $\begin{array}{l}\text { fps } \\
3.3 \\
3.1 \\
2.9 \\
2.7 \\
2.5\end{array}$ & $\begin{array}{l}{ }^{\circ} \mathrm{F} \\
\\
180 \\
182 \\
184 \\
186 \\
188\end{array}$ & $\begin{array}{c}f p s \\
5,000+ \\
99.2 \\
98.0 \\
96.7 \\
95.2 \\
93.6\end{array}$ & $\begin{array}{l}f p s \\
-1.0 \\
-1.2 \\
-1.3 \\
-1.5 \\
-1.6\end{array}$ \\
\hline $\begin{array}{l}40 \\
42 \\
44 \\
46 \\
48\end{array}$ & $\begin{array}{r}71.9 \\
88.2 \\
104.1 \\
119.6 \\
134.6\end{array}$ & $\begin{array}{l}16.8 \\
16.3 \\
15.9 \\
15.5 \\
15.1\end{array}$ & $\begin{array}{l}90 \\
92 \\
94 \\
96 \\
98\end{array}$ & $\begin{array}{l}68.5 \\
76.2 \\
83.6 \\
90.8 \\
97.7\end{array}$ & $\begin{array}{l}8.0 \\
7.7 \\
7.4 \\
7.2 \\
6.9\end{array}$ & $\begin{array}{l}140 \\
142 \\
144 \\
146 \\
148\end{array}$ & $\begin{array}{l}89.6 \\
91.7 \\
93.6 \\
95.3 \\
96.9\end{array}$ & $\begin{array}{l}2.3 \\
2.1 \\
1.9 \\
1.7 \\
1.6\end{array}$ & $\begin{array}{l}190 \\
192 \\
194 \\
196 \\
198\end{array}$ & $\begin{array}{l}91.8 \\
89.9 \\
87.9 \\
85.7 \\
83.4\end{array}$ & $\begin{array}{l}-1.8 \\
-1.9 \\
-2.1 \\
-2.2 \\
-2.3\end{array}$ \\
\hline $\begin{array}{l}50 \\
52 \\
54 \\
56 \\
58\end{array}$ & $\begin{array}{r}149.3 \\
163.6 \\
177.5 \\
191.0 \\
{ }^{*} 4.1\end{array}$ & $\begin{array}{l}14.7 \\
14.3 \\
13.9 \\
13.5 \\
13.1\end{array}$ & $\begin{array}{l}100 \\
102 \\
104 \\
106 \\
108\end{array}$ & $\begin{array}{l}* 4.4 \\
10.8 \\
17.0 \\
22.9 \\
28.6\end{array}$ & $\begin{array}{l}6.7 \\
6.4 \\
6.2 \\
5.9 \\
5.7\end{array}$ & $\begin{array}{l}150 \\
152 \\
154 \\
156 \\
158\end{array}$ & $\begin{array}{r}98.3 \\
99.5 \\
100.5 \\
101.4 \\
102.1\end{array}$ & $\begin{array}{r}1.4 \\
1.2 \\
1.0 \\
0.9 \\
.7\end{array}$ & $\begin{array}{l}200 \\
202 \\
204 \\
206 \\
208\end{array}$ & $\begin{array}{l}81.0 \\
78.4 \\
75.7 \\
72.9 \\
70.0\end{array}$ & $\begin{array}{l}-2.5 \\
-2.6 \\
-2.7 \\
-2.8 \\
-3.0\end{array}$ \\
\hline $\begin{array}{l}60 \\
62 \\
64 \\
66 \\
68\end{array}$ & $\begin{array}{l}16.9 \\
29.3 \\
41.3 \\
53.0 \\
64.4\end{array}$ & $\begin{array}{l}12.8 \\
12.4 \\
12.0 \\
11.7 \\
11.4\end{array}$ & $\begin{array}{l}110 \\
112 \\
114 \\
116 \\
118\end{array}$ & $\begin{array}{l}34.0 \\
39.2 \\
44.2 \\
48.9 \\
53.5\end{array}$ & $\begin{array}{l}5.4 \\
5.2 \\
5.0 \\
4.8 \\
4.5\end{array}$ & $\begin{array}{l}160 \\
162 \\
164 \\
166 \\
168\end{array}$ & $\begin{array}{l}102.6 \\
103.0 \\
103.2 \\
103.2 \\
103.1\end{array}$ & $\begin{array}{r}.6 \\
.4 \\
.2 \\
.0 \\
-.1\end{array}$ & $\begin{array}{c}210 \\
212 \\
\end{array}$ & $\begin{array}{l}66.9 \\
63.7 \\
\end{array}$ & $\begin{array}{r}-3.1 \\
-3.2 \\
\end{array}$ \\
\hline $\begin{array}{l}70 \\
72 \\
74 \\
76 \\
78\end{array}$ & $\begin{array}{r}75.4 \\
86.1 \\
96.4 \\
106.5 \\
116.2\end{array}$ & $\begin{array}{r}11.0 \\
10.7 \\
10.4 \\
10.1 \\
9.8\end{array}$ & $\begin{array}{l}120 \\
122 \\
124 \\
126 \\
128\end{array}$ & $\begin{array}{l}57.8 \\
61.9 \\
65.8 \\
69.4 \\
72.9\end{array}$ & $\begin{array}{l}\text { 4. } 3 \\
4.1 \\
3.9 \\
3.7 \\
3.5\end{array}$ & $\begin{array}{l}170 \\
172 \\
174 \\
176 \\
178\end{array}$ & $\begin{array}{l}102.8 \\
102.4 \\
101.8 \\
101.1 \\
100.2\end{array}$ & $\begin{array}{l}-.3 \\
-.4 \\
-.6 \\
-.8 \\
-.9\end{array}$ & - & - & - \\
\hline 80 & $\begin{array}{r}125.7 \\
4,800+\end{array}$ & 9.4 & 130 & $\begin{array}{c}76.2 \\
5,000+\end{array}$ & 3.3 & 180 & $\begin{array}{r}99.2 \\
5,000+\end{array}$ & -1.0 & ........... & $5,000+$ & $\ldots$ \\
\hline
\end{tabular}

Thus, the total uncertainty in the length of the tank is about $5 \mathrm{ppm}$ at $20^{\circ} \mathrm{C}$, and increases with temperature both ways; at $0^{\circ} \mathrm{C}$ it becomes about $9 \mathrm{ppm}$ and at $100^{\circ} \mathrm{C}$, about $21 \mathrm{ppm}$.

The question arises as to how closely the length of the sound path in the sample, i. e., the distance between the inner faces of the transducers, approximates to the length of the tank across the ends to which the crystals are wrung. Experience with developmental models showed that unless the assembly were very carefully made, with particular attention to avoidance of clamping pressure too near the unsupported areas of the crystals, the crystals might deflect enough to cause very sizable errors. The present design makes it possible to disassemble and reassemble the delay line repeatedly without affecting the result by a detectable amount; this holds true when the crvstals normally used, which are $0.8 \mathrm{~mm}$ thick, are replaced by crystals $1.6 \mathrm{~mm}$ thick. It, therefore, appears that errors produced by misplacement or deformation of the crystals are insignificant. 


\subsection{Setting the Coincidence}

As explained in section 2, it is believed that no measurable error is introduced by the technique of maximization of the second half cycle of the received pulse. However, a word should be said about the effect of personal bias on the part of the operator. The operators report, to varying degrees, tendencies to adjust not only for maximum height of peak, but also for maximum symmetry and sharpness of peak. Long experiment has convinced us that any of the three criteria lead to sensibly the same result, so that although different operators weigh the three criteria differently, they reproduce each other's settings so well that the discrepancies are negligible relative to other sources of error. The assumption is implicit that the errors of bias do not much exceed the discrepancies among individuals.

\subsection{Temperature}

The Mueller bridge with which the resistance of the platinum thermometer was measured has a least count of $0.0001 \mathrm{ohm}$ corresponding, for a 25 -ohm thermometer, to about $0.001^{\circ} \mathrm{C}$. The bridge was calibrated internally so that the indicated resistance in terms of the internal standard is correct to about $0.0002 \mathrm{ohm}$ aside from temperature effects and slow drifts in the arm ratio and in the zero. Allowing for these, it is estimated that the bridge error does not exceed $0.005^{\circ} \mathrm{C}$; errors in the calibration of the platinum thermometer itself and those due to heating by the bridge current are much smaller. More important is the error that arises from thermal gradients in the bath. On the assumption that this does not exceed half the reading of the differential thermocouple which, it will be recalled, measures the difference between the temperature of the platinum element and that of the sample, an upper limit to the corresponding uncertainty in the speed of sound, $c$, was calculated at various temperatures from the known thermal coefficient of $c$. This upper limit is zero at $74^{\circ} \mathrm{C}$, where $c$ is stationary and increases steadily in both directions, reaching about $25 \mathrm{ppm}$ at $0^{\circ} \mathrm{C}$, and about $14 \mathrm{ppm}$ at $100^{\circ} \mathrm{C}$.

\subsection{Purity of Sample}

Because the results obtained on ordinary laboratory distilled water were indistinguishable from those obtained on the same water redistilled in vacuum directly into the apparatus, it is felt that the remaining impurities do not have a measurable effect. Several measurements made on local tap water gave results about $30 \mathrm{ppm}$ higher than for distilled water.

\subsection{Over-all Accuracy}

From the foregoing discussion it appears that the major sources of error are the uncertainties in the length of the path and in the temperature. Both of these are temperature dependent; their sum is an upper limit to the total error. This is about 35 ppm at $0^{\circ} \mathrm{C}$; it falls to $15 \mathrm{ppm}$ at $40^{\circ} \mathrm{C}$ and is almost constant at this value out to $70^{\circ} \mathrm{C}$, and rises to about $35 \mathrm{ppm}$ at $100^{\circ} \mathrm{C}$. It is upon these considerations that the recommendations for the use of the tables in section 4 are based.

The values of $c$ here reported are lower than those of most other workers, in particular the value at $30^{\circ} \mathrm{C}$ is about $0.4 \mathrm{~m} / \mathrm{s}$ below that of Del Grosso, Smura, and Fougere [3], whose work with the ultrasonic interferometer is perhaps the most carefully planned, executed, and analyzed work of this type to date. It was, therefore, felt desirable to perform an independent experiment using an apparatus and a method as different as possible from those of both Del Grosso, et al., and ourselves. An apparatus was constructed with which it is possible to measure, as a function of distance, the phase on the axis of a beam of progressive waves emitted by a small pistonlike radiator. If the wave were plane, the phase $\varphi$ would vary linearly with distance $x$, and the phase speed $c$ would be $2 \pi f x / \varphi$ where $f$ is frequency. In the present case, the wave is not plane and the slope of the curve $2 \pi f x$ versus $\varphi$ depends on $x$ and on the geometry of the arrangement. However, the theory enables us to select a distance $x_{0}$ of the receiver from the source such that for $x>x_{0}$ the departure of $2 \pi f d x / d \varphi$ from $c$ is as small as desired.

Five runs were made in distilled water at temperatures between $15^{\circ}$ and $25^{\circ} \mathrm{C}$. The principal uncertainties are thought to be first, one of about 40 ppm corresponding to a possible error of $0.01^{\circ} \mathrm{C}$ in the temperature, and second, one of about $56 \mathrm{ppm}$ related directly to the inaccuracies of the screw with which the receiver displacement was measured. These are independent. However, in the worst case of the 5 , the result differed from the value gotten from table 2 by only $27 \mathrm{ppm}$. The value of Del Grosso, et al. [3] disagrees with that of table 2 by 272 ppm.

This work will be reported in detail elsewhere.

The authors are grateful to the personnel of the Engineering Metrology Section and of the Length Section, in whose Laboratories the length of the tank and its thermal expansion, respectively, were measured. Thanks are particularly due to Joseph M. Cameron of the Statistical Engineering Section who advised the authors on problems of data processing, and who performed the curve-fitting computations on SEAC.

\section{References}

[1] Martin Greenspan and Carroll E. Tschiegg, Sing-around ultrasonic velocimeter for liquids, Rev. Sci. Instr. (in press).

[2] R. A. MeConnell and W. F. Mruk, Microacoustic interferometer using 30 Mc pulses, J. Acoust. Soc. Amer. 27, 672 (1955).

[3] V. A. Del Grosso, E. J. Smura, and P. F. Fougere, Accuracy of ultrasonic interferometer determinations, NRL Report 4439, Naval Research Laboratory, Washington, D. C. (Dec. 6, 1954).

[4] Martin Greenspan and Carroll E. Tschiegg, Effect of dissolved air on the speed of sound in water, J. Acoust. Soc. Amer. 28, 501 (1956).

Washington, March 27, 1957. 